\title{
Critical Analysis and Current Challenges Facing HRIS Adoption in Arab Countries - the Case of Saudi Arabia \\ Alhazemi, Abdulrahman A. University of Jeddah
}

\section{Abstract}

Human Resource Management (HRM) system has become a necessity in the changing business technology services to meet global competition. The organisations around the world are increasingly adopting Human Resource Information System (HRIS) to gather deeper insights into the nature and performance of their human resources as well as to identify the various different means to develop the quality of these resources. Moreover, $\mathrm{HR}$ is especially important in a knowledge-based Information Technology (IT). Information technology has permeated through a number of different fields of management during the recent years. Human resources management is once such field that has benefited immensely from the development in computing power and Internet capabilities. The centralised HR departments in multinational organisations attempt to monitor the performance of employees across geographical borders using scientific measures and also attempt to provide services to employees around the world using centralised systems, which help to standardise the HR practices and to reduce the costs associated with maintaining multiple HR departments. Human Resources Information Systems (HRIS) help to accomplish these seemingly difficult tasks of centralised HR department in an easier manner. The growing importance of HRIS is due to the recognition of HR practitioners that IT and IS should be a part of HR functions mainly to develop better HR programmes. Even though HRIS has been touted as a major development in the area of HRM, it is noted that there are some very important issues associated with the decisionmaking with respect to HRIS and the implementation of the system. Even though a number of researchers have focussed on the issues and problems faced by the organisations, it is noted that very few researchers have studied the special problems faced by developing organisations. HRIS, which was used originally by very large multinational companies, has now been adopted even by smaller organisation as it provides the benefits of scientific management of human resources. This research attempts to study the various issues faced by the organisations in Arab countries ${ }^{1}$. It also attempts to ascertain if the issues faced are different for small and large organisations. Primary research methodology is adopted to accomplish these objectives. Accordingly, a detailed process of data collection is undertaken to collect data from a range of participants who represented different organisations engaged in one of the four different kinds of businesses - IT, trading, manufacturing and services. It is noted that the problems faced by small organisations are quite different from those faced by the large organisations. Following conclusions are made on the basis of the data analysis.

Keywords: Human Resources Management, Human Resources Information Systems, Human Resources practices, Human Resources department, Business Technology Services, University of Jeddah, Saudi Arabia.

\section{Introduction}

Organisations become what they are as a result of the efforts of the human resources that they possess. Although there are other resources and new features as well, such as capital building, machinery or technology, etc., which make the organisations competitive but without the contribution and efforts of human resources it is not possible for organisations to gain and sustain this competitive advantage (Hagood and Friedman, 2002; Ngai and

\footnotetext{
${ }^{1}$ UNESCO identifies 21 Arab states, while Wikipedia lists 23 Arab states. In addition, the Arab League is a regional organization of these states that was formed in 1945. It currently has 22 members.
} 
Wat, 2006; Chmeilecki, 2012). Human resources management is one such field that has benefited immensely from the development in computing power and Internet capabilities. The centralised HR departments in many large organisations are now able to manage human resources more efficiently across geographical borders using scientific measures. They are also able to provide services to employees around the world using IT enabled centralised systems which help to standardise the HR practices and to reduce the costs associated with maintaining multiple HR departments. Human Resources Information Systems (HRIS) help to accomplish the seemingly difficult tasks of centralised HR department. Ngai and Wat (2006) define HRIS as "the composite of databases, computer applications, and hardware and software necessary to collect, record, store, manager, deliver, and present data for human resources". According to Chmeilecki (2012: 52), "Futurists say one thing is certain - HR executives will play a vital role in helping business organisations compete". HRISs which was used originally by very large multinational companies, has now been adopted even by smaller organisation as it provides the benefits of scientific management of human resources.

New business environment is changing rapidly and organizations have to develop HR department in order to achieve competitive advantages. As stated earlier most of the researches in HRIS so far have focused on developed countries, particularly the US (Kavanagh and Thite, 2008). Brockbank (1999) states that the HR functions are typically considered as administrative functions and the HR managers are typically not included in strategic decision-making in a significantly large number of organisations. The development of HRIS applications is considered vital for HR Departments in almost every organisation. This is an important limitation, which curtails the power of HR manager to convince the management of the benefits and necessity of adopting HRIS. Jossi (2000) argues that the managers with power in organisations typically tend to perpetuate the common practices with respect to HR and do not wish to bring about any revolutionary changes in HR activities or strategies as they consider HR department to be a cost-centre rather than a profit-centre. There are a lot of opposition faced by HR department for the adoption of HRIS as the information system tends to be expensive while considering the HR budgets. Several changes are taking place in the IT landscape and HR Departments of Saudi Arabia, which is emerging as a big investor in all of them. Researchers such as Ceriello and Freeman (1999) and Hagood and Friedman (2002) have identified challenges related to HRIS eve during the post-implementation stages. One of the biggest problems is that the employees tend to ignore the benefits of the new system and show resistance towards using the system fully. It is important to note that developing countries including some Arab countries in the Gulf region such as the United Arab Emirates and Saudi Arabia are not different in managing change especially in public administration (Alharbi, 2002; Khassawneh, 2005; Alhazemi A. A. 2016; Dore, 2006; Rees \& Althakri, 2008). Alharbi (2002) argues that most strategic change initiatives in the Arab region fail because most managers do not have a clear sense of direction for their organisations. It is therefore not surprising that one of the most important challenges facing any organisation is managing organisational change successfully (Burnes, 2003).

This research is also expected to have significant organisational importance as it is seen from the review of Beulen (2009), Ceriello and Freeman (1999) and other researchers that small organisations face problems that are quite different from those that are faced by large organisations while implementing HRIS. Since this research focuses on the organisations in the chosen geographical region, it is expected that the observations and conclusions made by this research would be of significant value and interest to the small organisations not only in Saudi Arabia but also in other developing regions of the world. 


\section{Literature Review}

This research aims to focus on the issues and challenges faced by organisations in developing and Arab countries when they attempt to implement business technology services. Besides, change implementation is a high-risk process with a high potential for failure if it is not properly directed by management. Hammer and Champy (1993) estimate that as much as 70 per cent of Business Process Re-engineering (BPR) projects fail (See Judge \& Douglas, 2009). In addition, Burnes (2003), states that the failure rate of new technology change is between $40 \%$ and $70 \%$. A number of scholars including Kotter (1996), Hartley (2002), and Wall (2005), indicate that fewer than $30 \%$ of change initiatives are successful. Oakland and Tanner (2007), support this evaluation by reporting that the success rate of change programmes could be as low as $10 \%$. For instance, over $80 \%$ of total quality management initiatives by the United Kingdom and European organisations fail, and research suggests that failed organisational change initiatives range from onethird to as high as $80 \%$ of attempted change efforts (Knodel, 2004; Kotter, 2008; Burke, 2011).

It is likely that the small organisations face problems that are different from those faced by large organisations. This observation is made on the basis of research by Beulen (2009) who, in his research, notes significant differences between the problems faced by small organisations and large organisations. Some of the problems that are likely to be identified from this research are the cost of HRIS, lack of importance to HR department, lack of power of HR manager, the long time period associated with HRIS implementation, the training needs, employee inertia etc. A detailed review of existing literature is undertaken before embarking on primary research to ensure that critical knowledge about the subject of HRIS as well as the challenges faced by the organisations during the implementation of HRIS are obtained. It is believed that this critical knowledge would help to design the primary research appropriately including the preparation of questionnaire. The observations made in literature review may also be useful in analysing the results of primary research. In the fourth chapter of this dissertation, the observations made on the basis of literature review are compared to the observations made on the basis of analysis of primary data. The differences and similarities between these two sets of observations are discussed and analysed. On the basis of these similarities and differences between these observations, discussion and analysis, conclusions are drawn. Thus literature review forms a very important part of this research. This chapter is divided into three important sections. The first section critically analyses the different definitions of HRIS as well as the concept of HRIS in detail. This section presents the fundamental understanding of the concept. The second section is concerned with the analysis of various issues and challenges related to implementation of HRIS during the different stages, as identified by other researchers. The second section brings attention to broader issues. The third section is related to the challenges faced by organisations in developing countries while choosing and implementing HRIS in their establishments. The third section focuses attention on the specific problems in developing countries (Burnes, (2003), Beulen, (2009), Ceriello and Freeman (1999).

\section{Current Challenges}

A number of researchers have identified various different factors that are known to cause changes in the organisations related to implementation of HRIS. The organisations choose specific change strategies in response to these changes to which they are driven by these factors. Broadly the drivers of change can be classified into external and internal. The external drivers are those that exclude the organisation itself and are concerned mostly with the environment in which they operate. Senior (2002) identified four different kinds 
of external change drivers. They are Political, Economic, Socio-Cultural and Technological. This is popularly known as the 'PEST model'. The political drivers include legislative changes created in the legal environment, which compel the organisations to change as well as the structural adjustments that are caused by the shift of power balance within the organisation. The economic factors include changes in macroeconomic environment such as inflation and interest rates. It could include the changes in economic policies such as changes in taxes and cutbacks in aids offered to the businesses. The Sociocultural factors that compel change include the demographic trends as well as changing attitudes towards specific kinds of works (Paton and McCalman, 2000). For example, if doing clerical work is increasingly looked down upon by the society, then in order to ensure that the organisation attracts good employees to do the clerical work, it is necessary to outsource it to a country or a place where people are still attracted to clerical work. Collins (2000) identifies that management change fad could also drive the organisations towards change as it becomes a trend in the society to speak and engage in change management. Technological factors that cause change include development of new information and communication technologies such as broadband and videoconferencing, which allow virtual employees to participate in the main processes. There are some strategic drivers at macro level. Globalisation is stated to be one of the most important drivers of change in every country and region. Globalisation has opened the gates for competition not only from within the country but from abroad. As companies learn new strategies and lessons they compete harder and stronger which leads to more changes in them. Innovation is also stated to be a major driver of change as it is seen that it tends to redefine the paradigms of possibility for various products and services (Cameron and Green, 2004).

It is also observed that most researchers have focused on the developed West and very few have actually focused on the Arab region. However the handful of researchers who have studied the Arab region have found significant issues related to strategic change management in the region. Alqahtani (2006) states that most organisations in the Arab world do not have a clear agenda for strategic change and organisational development, the result of which strategic change efforts fail in the region, particularly in the Gulf countries. Thus, focusing on the Arab region from the context of strategic change drivers would enable this research to add significant value to the body of knowledge on the subject. Beulen (2009) argues that the challenges faced by organisations with respect to HRIS could be different in Arab countries and so HRIS needs to be localised to a significant extent. The brief literature review presents basis for arguing that there are challenges to be faced during the decision-making, pre-implementation, implementation and postimplementation stages of HRIS as that those challenges could be different in Arab countries such as Saudi Arabia which is the largest economy of the middle-east as well as the fastest growing economy in the region Alhazemi A. A, (2016). The World Bank Group report said the Saudi Arabia is among the top 20 reformist countries in the world, and the second among the top high-income countries in the G-20 countries in terms of implementing reforms to improve the business climate. However, In 2016, the Saudi economy expanded by 1.4 percent, slowing notably from 4.1 percent in 2015. This represents the slowest growth rate since 2002, when overall GDP expanded by 0.1 percent. A smaller increase in oil production, by 2.4 percent, meant a slower oil sector growth at 3.4 percent. Meanwhile, annual growth in the nonoil private sector was nearly flat at 0.1 percent. This is particularly the case as the commitment to increase the role of the private sector in the economy under the National Transformation Program and Vision 2030 would present many opportunities for lenders. Generally, banks in Saudi Arabia are profitable, liquid, and well-capitalized . (see Miyajima, 2017). 
Using these scientific methods, it is now possible to focus on each employee's talents and abilities and mould them to achieve the level of performance that the organisation expects from them. Another major benefit of HRIS is that it helps to integrate human resources information with other strategically important information in the organisation. The highly integrated set of data and/or information may be able to provide better decision-making capabilities to the management (Peng, 2008). This is the case because HRIS provides a highly integrated system to acquire, distribute, store and retrieve critical information related to employees which could play important roles in developing the productivity and efficiency.. HRIS may also help to plan the training needs and to draw HR plan as well as to identify HR gaps (Peng, 2008).

This research attempts to study the challenges faced by organisations in Arab countries when they attempt to harness the powers of HRIS to the maximum extent possible. This research uses the case of Saudi Arabia as a representative of the Arab countries. Saudi Arabia is chosen as the representative of the Arab countries on the basis of the fact that the country is one of the fastest growing economies in the world. Saudi Arabia is chosen over other contenders such as United Arab Emirates, Kuwait and Egypt due to the fact that Saudi Arabia has established its name in IT services in the global market. The government's aim of reaching a balanced budget in 2020, as oil prices are expected to rally further and the economic diversification away from oil should lead to additional revenues. This research examines the case of Saudi Arabia to understand the difficulties faced by organisations that attempt to implement HRIS in their organisations. Findings from this research have both academic and organisational importance. The academic importance attributed to this research stems from the fact that very few researchers have attempted to identify the challenges that faced organisations of different sizes particularly in developing countries while considering the option of HRIS as against the existing system of HR functions. Most of the research so far in this area of study has focused on the developed countries such as the US and UK. This research aims to fill this gap by focusing precisely on organisations in one of the developing countries - Saudi Arabia . The growth of technologies systems in the Kingdom could then become a great solution for local companies to upgrade the capabilities and ingenuity of their HRs, allowing them to perform their certain tasks, structures, responsibilities and functions rapidly with greater accuracy (Afiouni, Ruël and Schuler 2014).

\section{HRIS - Definition and Concept}

A number of researchers have studied the various aspects of HRIS. While some researchers have attempted to define HRIS in a comprehensive manner by identifying the various activities involved in HRIS, others have tried to define HRIS through its different objectives. Poutanen (2005) states that, "HRIS is a tool used by the whole organisation to provide information on employees for management, HR professionals and personnel to increase the organizational well-being and effectiveness." This definition outlines the important aspects of HRIS which according to Poutanen (2005) is about providing information to different stakeholders in the organisation in order to promote organisational effectiveness. It is implemented to assist productivity gains and developments within the organisation. Poutanen's definition of HRIS is focused more on the results of implementation of HRIS rather than HRIS itself as it is believed that HRIS is a tool to achieve organisational objectives. Tannenbaum (1990) presents an alternative definition which is focused only on the process involved. He argues that HRIS is a system that is used to "acquire, store, manipulate, analyse, retrieve and distribute information about an organisation's human resources" (Tannenbaum, 1990). Contrary to Poutanen's (2005) definition, the focus here is on the various activities involved in HRIS. Kovach and 
Cathcart (1999) present a definition of HRIS which is more comprehensive in terms of both the processes involved as well as the ultimate objectives of these processes. They argue that "an HRIS is a systematic procedure for collecting, storing, maintaining, retrieving and validating certain data needed by an organisation about its human resources, personnel activities and organisation unit characteristics" (Kovach and Cathcart, 1999). At a broader level, HRIS involves the use of technology and computer networks to create and store large quantities of data and information related to the HR functions such as job description and mapping, recruitment, selection, pay, performance, HR policies, retention, retrenchment etc. Researchers often refer to HRIS as e-HR as it involves the use of electronic medium to manage human resources. It is also noted that HRIS is mostly concerned with those information that could be of use for the HR department of the organisation (Burnes, (2003), Beulen, (2009), Ceriello and Freeman (1999), (Kovach and Cathcart (1999).

According to Martinsons (1994), HRIS may be classified into two different categories on the basis of the nature of uses of HRIS. The "unsophisticated" use of HRIS involves transformation of simple administration functions into electronic form. The various activities including preparation of payrolls and employee absentee records list are considered unsophisticated uses of HRIS as these, at best, represent a simple upgrading of the existing activities into electronic form. However, there are some activities in HRIS which are considered "Sophisticated" as they represent a paradigm shift in the functions of HR. Some of these sophisticated uses are selection, recruitment, job profile matching, employee progress monitoring, pay-performance balancing, efficiency improvement, etc. While the unsophisticated uses of HRIS are mostly administrative in nature, the sophisticated uses are closely related to the high-level HRM functions of the organisations. Many researchers have identified some of the common advantages and disadvantages of HRIS. Some of the most important and direct advantages of HRIS are that it could lead to better accuracy of computations as well as improvement in efficiencies of human resources in the organisations (Ceriello and Freeman, 1998). Kovach and Cathcart (1999) note that the most important function of HRIS is to provide analytical decision support to the organisation. Specifically, HRIS provides support to the management of the organisation to make some of the most important strategic decisions. These are typically long-term in nature and could affect the very existence or growth trajectory of the organisations. The HRIS may have the necessary information related to the efficiency or productivity of employees as well as the pattern of development in the knowledge creation process within the organisation. Besides, it may also help to identify the gaps between the existing level of knowledge and skills and the levels expected to be attained so as to meet the organisational objectives and targets (Bohlander and Snell, 2009).

Mayfield et al., (2003) state that the role of HRIS is to function as an operational link between strategic vision and HR implementation. Mayfield et al., (2003) state that achievement of vision and objectives require significant investments in HR and knowledge creation, which are aided by the HRIS. This argument is based on the resource-based theory of HRM. The resource-based theory states that Human resources could be used as the competitive resources owned by the firm and so it is possible for a firm to build significant competitive advantages over its rivals in the industry by focusing on development and retention of HR resources (Mayfield et al., 2003). Mayfield et al., (2003) developed a model for HRIS on the basis that HRIS should help an organisation realise its vision. Accordingly, the model includes seven components - "strategic integration, personnel development, communication and integration, records and compliance, HR analysis, knowledge management, and forecasting and planning". It is stated that each one 
of the seven components plays pivotal role in ensuring that the organisation achieves its strategic vision.

An analysis of the different definitions of HRIS as well as the basic model and concept of HRIS clearly shows that HRIS is associated with electronic storing and retrieval of critical information related to the HR wealth of an organisation. These information are intended to help promote the efficiency of labour as well as to aid the achievement of the strategic objectives of the organisation. Following the discussion on the concept and theory of HRIS, the next section will review some of the most prominent issues and challenges faced by organisations when they attempt to make HRIS decisions and implement HRIS (Beulen,2009; (Kovach and Cathcart,1999; (Mayfield et al., 2003).

\section{HRIS - Issues and Challenges}

Even though most of the literature reviewed so far have emphasised on the positive sides of HRIS for the organisations, some researchers (Hannon et al., 1996; Campbell et al., 2002) have drawn attention to the fact that HRIS implementation is not a simple affair. this is because the decisions to adopt HRIS and the process of implementation are riddled with problems and issues of varying levels including pre-implementation, implementation and post-implementation. Willcocks and Feeny (2006) report the findings on the basis of a longitudinal study of IT outsourcing by Dupont, conducted over a period of seven years. Dupont is a large conglomerate with business interests in chemicals, energy, health care, materials and agriculture. The organisation recognised the need for outsourcing its IT and IS activities in 1997 and signed a series of ten-year deals with Computer Sciences Corporation CSC and Anderson Consulting (later renamed Accenture). CSC took care of the shared infrastructure services worldwide while Accenture's main task was to manage the Chemical division's business enterprise applications. After outsourcing over $80 \%$ of the IT budget and transferring $75 \%$ of its employees in IT divisions, Dupont realised significant cost savings of up to $39 \%$ of the fixed IT costs and also found quick skills injection. However subsequently four years into the deal Dupont realised that it had retained too few management and IT talent and activities to ensure its IT future. In 2000 Dupont began recreating some of its core capabilities in IT, which it had already outsourced. The organisation also recruited key technical resources following which it renegotiated its outsourcing deals with its alliance partners (Hannon et al.,1996); Campbell et al., 2002), Willcocks and Feeny (2006).

In order to streamline the discussion on the issues and challenges faced by organisations in relation to HRIS, this section is divided into three sub-sections. These sub-sections include the issues related to HRIS during the pre-implementation stage, the implementation stage and the post-implementation stage (Hannon et al., 1996); Campbell et al., 2002), Willcocks and Feeny,2006).

\section{Pre-Implementation Stage}

Pre-implementation stage is the most important in the HRIS decision-making as it typically involves the management and the HR department conducting a detailed feasibility study of the HRIS in terms of both costs and benefits and finally arriving at the decisions as to whether to adopt HRIS or not. There are a number of issues involved in this stage as it is seen that the members of the management typically tend to carry certain notions of HR in general and HRIS in particular, which play very important and influential roles in determining the final decisions. Hannon et al. (1996) state that the management of the organisation may have a tendency to delay or avoid making decisions on HRIS as it is observed that HRIS is typically cost-intensive in nature and in most cases require a redefinition of the various HR processes and activities throughout the organisation. Since 
the benefits of implementation of HRIS would begin to accrue only after the implementation is completed, the management may not have a way of reaffirming their confidence in HRIS through a process of trail or part implementation. Besides, once the management team rejects the idea of HRIS, it could be difficult for them to accept it later due to the inherent tendency of human beings to vindicate their decisions through actions (Campbell et al., 2002). Thus the management team as well as the Board of Directors of the companies may pose the biggest threat of HRIS in the initial stages.

In terms of value, Lawler (1995) and Brockbank (1999) show that organisations typically tend to attach low importance to the HR managers when compared to other 'core' operational managers. Even though HR heads are considered to be at a level at par with the departmental heads, the strategic meetings typically tend to exclude HR managers and include only those who are actively involved in production, marketing and finance functions (Mathis and Jackson, 2008). Even though the thought of personnel management has evolved into a full-fledged HRM many years ago, there is still a tendency to view HRM as a supporting function and not as an integral function of critical decision-making in the organisation. This lower level of importance attributed to HR department may be due to the fact that administration continues to remain one of the functions of HR department in most of the organisations. Due to this lack of power of HR managers, it may be difficult for the HR head and other managers of the department to successfully lobby for adoption of HRIS with the management (Tansley and Watson, 2000).

Besides the decision to adopt HRIS, the next biggest issue during the pre-implementation stage is related to the decision related to outsourcing of HRIS implementation. Organisations believe that they should be careful about providing external access to the vital records in HR departments. Organisations that do not have any core IT or implementation knowledge may be sceptical about outsourcing implementation of HRIS due to fear of compromise of privacy and secrecy (Greer et al., 1993). Some organisations choose to shelve the idea of HRIS right at the point where they are compelled to outsource the activities to a third party. Taplin (2007) dispels the notion that organisations with systems knowledge may understand the benefits and so may come forward to outsource. Rather, Taplin (2007) argues that these organisations, due to their intricate knowledge of the problems that could be caused by identify and information theft, typically tend to be more hesitant than other organisations in outsourcing their HRIS implementation activities. It is observed from this discussion that security and privacy are some of the key issues involved in HRIS outsourcing decision Brockbank (1999), Budhwar and Bhatnagar (2009), Mathis and Jackson (2008).

\section{Implementation Stage}

Implementation of HRIS could be a long process which does not simply begin and end with the HR department. HRIS implementation requires that the employees, who are the clients of the HR department understand the processes and procedures and come forward to utilise the facilities provided so that the benefits from HRIS be realised. Problems arise due to the fact that the employees may have gotten used to certain ways of doing things and so may exhibit a certain level of inertia to move on to a different system, even though the system is more evolved and easier to use (Jossi, 2000). The lack of familiarity with the HRIS may create a notion that HRIS could be difficult and too sophisticated for the benefits that it provides to the users. The users of the HRIS need to be trained properly to gain familiarity with the system. However during the process of training, the lack of computer literacy could become a major issue as those employees who do not happen to be involved with computers in their regular line of work may feel significant stress in being expected to learn computers and so may find the task daunting. Specifically, since the 
training is not related to their core operational functions, the employees may not realise the value that it adds to their knowledge and careers (Elliott, 1999).

Another major issue during the implementation stage may be related to the process of customisation. HRIS is not simple productivity software that could be installed and used right out of the box. In order to harness the powers of HRIS, the HR departments needs to work with the development and implementation team to ensure that the modules and processes are customised to suit the existing activities and processes in the HR department. Singh (2002) finds that one of the major reasons for failure of HRIS is that the HR department tends to changes it rules and practices to suit the HRIS rather than customising the HRIS to reflect the practices Jossi (2000), Elliott (1999), Singh (2002), Lambin (2005).

\section{Post-Implementation Stage}

HRIS requires continuous monitoring of the performance of the system so that appropriate changes could be made whenever it is required. It is noted by Ceriello and Freeman (1999) that the HR department as well as the functional managers such as those in finance, operations, procurement departments etc., tend to relax and push the HRIS to the back burner once the implementation process is completed. In order to ensure that the system develops into a more suitable one for the organisation, it is essential to ensure that the new practices and procedures adopted by the HR department are replicated accurately in the system as well. Thus HRIS requires continuous development support from the vendor when the system is developed by external agents. When the vendor is not equipped with the resources to continuously develop the system, the usefulness and utility of the system for the organisation diminishes significantly over time. Besides, HRIS requires continuous maintenance of database systems and security systems so that the information gathered is secured from conscious and unconscious losses and interventions (Ceriello and Freeman, 1999). Thus, maintenance of HRIS could be cost intensive dependent on the extent of usage as well as the size of the organisation. If the organisation does not have the IT talent and resources to maintain HRIS, they may need to outsource the maintenance programs to external agencies well equipped to do so. This may create a continuous maintenance cost which may not suit the budgets of particularly small organisations (IOMA, 2002).

However, the biggest problem during the post-implementation stage could develop right within the HR department. The HR managers are expected to develop their IT proficiency so that they may be able to extract and use the information collected and stored by the HRIS. If the HR managers do not quickly traverse the steep learning curve and gain fluency with the use of technology, the organisation may not be able to achieve the planned benefits from HRIS (Hagood and Friedman, 2002). There is also a risk that HRIS may fall short of the expectations of the senior management. The senior management may not realise that HRIS is just a tool that may make their decision-making a little easier and scientific .

Thus, it can be argued that the organisations that choose to adopt and implement HRIS face a host of challenges and issues all along the entire process. The issues span across all the major stages including pre-implementation, implementation and post-implementation of HRIS (Hagood and Friedman, 2002). In the next section, we address how these challenges play-out in developing countries

\section{HRIS - Challenges in developing countries}

Researchers such as Ceriello and Freeman (1999) and Hagood and Friedman (2002) have identified challenges related to HRIS eve during the post-implementation stages. One of the biggest problems is that the employees tend to ignore the benefits of the new system 
and show resistance towards using the system fully. It is important to note that developing countries including some Arab countries in the Gulf region such as the United Arab Emirates and Saudi Arabia are not different in managing change especially in public administration (Alharbi, 2002; Khassawneh, 2005; Dore, 2006; Rees \& Althakri, 2008). Alharbi (2002) argues that most strategic change initiatives in the Arab region fail because most managers do not have a clear sense of direction for their organisations. It is therefore not surprising that one of the most important challenges facing any organisation is managing organisational change successfully (Burnes, 2003). In the last two decades however, many Arab countries have been shifting their economic structures from socialist oriented trends in the 1960s and the 1970s towards a mixed economy or social market economy to deepen Arab economic integration (Hoekman and Sekkat, 2010). Furthermore, several Arab countries who are members of the Gulf Cooperation Council are recently making considerable economic improvement to achieve a modern, liberal, and open economy. For instance, the Saudi government attempts to cope with global changes and to improve the economy, workplace environment, and HRIS performance (Ministry of Economy and Planning, 2010).

It is also observed that most researchers have focused on the developed West and very few have actually focused on the Arab region. However the handful of researchers who have studied the Arab region have found significant issues related to strategic change management in the region. Alqahtani (2006) states that most organisations in the Arab world do not have a clear agenda for strategic change and organisational development, the result of which strategic change efforts fail in the region, particularly in the Gulf countries. Thus, focusing on the Arab region from the context of strategic change drivers would enable this research to add significant value to the body of knowledge on the subject. Beulen (2009) argues that the challenges faced by organisations with respect to HRIS could be different in Arab countries and so HRIS needs to be localised to a significant extent. The brief literature review presents basis for arguing that there are challenges to be faced during the decision-making, pre-implementation, implementation and postimplementation stages of HRIS as that those challenges could be different in Arab countries. HRIS may have some very important advantages to offer to organisations from less developed and developing countries. This is due to the fact that HRIS can quickly align the workforces in these organisations along their strategic objectives thereby providing significant advantages over their less sophisticated rivals in local markets. On the other hand however, the adoption and implementation of HRIS in developing countries could be more troublesome form many various reasons. This brief section is focused on those factors that have been identified by researchers to play some unique and special role in hindering the adoption of HRIS in developing countries Ceriello and Freeman (1999), Hagood and Friedman (2002), (Heeks, 2002).

The primary problem in HRIS adoption in developing countries stems from the low level of importance attributed to HR functions in general. In Saudi Arabia for example the HR has traditionally been held in "reactive mode" in Saudi Arabia corporate sector. This means that the HR functions are brought into picture only when there is a need. The role of HR department has traditionally been limited to problem solving between management and employees. Due to this attribution of low level of importance to HR functions, one major problem develops. The HR managers are typically powerless and so they may not be able to push through a proposal for HRIS with the management (Langbert and Friedman, 2002). Another problem with HR departments in developing countries is that the budgets for these departments tend to be significantly smaller than their counterparts' in the developed countries (Heeks, 2002). 
HR department is considered a cost-centre and not a profit-centre and the HR department does not have any income of its own. Thus its cost has to be apportioned to other productive departments and so may be considered a drag on the performance of the profitcentres in the organisations (Heeks, 2002). Due to this reason, the heads of the profitcentres may be hesitant to recommend or support any change that could reduce their profitability. Since HRIS is a major sunk cost for the HR department, it is unlikely to be received with much fanfare among the heads of departments as well as among the members of the senior management teams (Lambin, 2005).

\section{Methodology of solution}

The primary aim of this research is to critically analyse the case of Saudi Arabia to ascertain the typical problems faced by organisations adopting HRIS in Arab countries. In order to accomplish this objective this research adopts primary research methodology, which involves collection of first-hand information from a set of respondents (Kolb, 2008 The first section explains the research philosophy underlying the methodology while the second section presents the methodology adopted. The subsequent sections explain in detail the rationale behind the choice of sampling method and questionnaire design. The various ethical issues are discussed later. This research includes a secondary research using literature review. The observations made from this literature review are used as the basis of designing and implementing the primary research. This chapter presents in detail the various factors that go into determining the final research design for this study. This chapter explains the research philosophy underlying the methodology adopted. It then proceeds to explain the research methodology along with the alternatives considered and the justification underlying the choice.

The primary research methodology adopted in this research requires that a suitable sample be chosen and an appropriate data collection tool be employed because primary research involves drawing observations and inferences about a population using a small subset drawn from the population (Bryman, 2001). This chapter explains the rationale underlying the sampling method followed and the results obtained. The questionnaires, used for data collection in this research are chosen after deliberation about the merits and demerits of various methods of data collection, all of which are specified in this chapter. The various limitations of this research are also identified in this chapter. There are a number of ethical considerations that need to be addressed mainly due to the primary research methods adopted. Therefore, these ethical issues that are of importance and the way in which this research deals with these issues are explained. Thus, this chapter presents a comprehensive round up of the methodology followed by this research.

\section{Research Philosophy}

This research adopts the philosophy of interpretivism to accomplish its objectives. The interpretive epistemological position asserts that a knowledgeable researcher should interpret the behaviour of various social actors in order to acquire knowledge about the actor as well as the environment in which the activities take place (Willis et al., 2007). Interpretivism also requires that the different activities be analysed using the knowledge collected from various sources. More specifically, this philosophy means that the environment plays an important role in the process of interpretation. Therefore the processes as well as the performers should be studied in appropriate context in which the actions take place. In this research, information are collected from the respondents and they are interpreted using the knowledge acquired using the review of literature related to the topic of HRIS in general and HRIS in developing countries in particular. The most important advantage of interpretivism is that it does not isolate the human beings from 
their environment. The interpretations are made with respect to the context and the environment in which the actions take place.

\section{Research Approach}

There are three basic research methodologies that are typically adopted by academic researches. This section identifies these three methodologies and compares their merits and demerits. The secondary research methodology is considered one of the simplest and easiest to follow as it typically involves critical analysis of the existing body of knowledge and secondary data on the subject. This methodology produces the most efficient results when there is a wealth of knowledge on the subject and also when there are more recent and relevant data and information abundantly available (Bryman, 2001). However, it is seen that in most cases secondary data are usually available after a certain time lag, which is associated with collecting and publishing data. Due to these limitations secondary data may be suitable only for cases when adequate and relevant data may be readily available from a source, which is dependable as an acceptable data collection methodology (Bryman and Bell, 2007).

The second methodology commonly used is empirical research methodology. In empirical methodology, the researcher identifies a model, which helps to make observations about the subject on hand, and attempts to verify the validity of the model using a set of relevant data (Schwab, 2005). Empirical research also includes the grounded research method where the process is reverse of the traditional empirical research. These data are typically collected from secondary sources. However the limitation of empirical methodology is that it may not be very helpful in qualitative researches as well as those that do not have a dependable set of data readily available (Koib, 2008). This research adopts primary research methodology due to the fact that the peculiar conditions which this research attempts to study may require directly relevant data to be collected firsthand by the researcher.

Primary research methodology involves collection of relevant data from a sample of respondents specially identified for the purpose of the research (Cooper et al., 2009). Primary research emphasises on collecting data in a manner that would minimise the possible biases in the data. This is achieved by ensuring that the sample represents the population significantly. It is essential that the sample selection process ensures that a suitable sample is selected. The biggest advantage of primary research when compared to other methodologies is that it results in a data set which is highly relevant to the research and so, it is likely to produce results, which are objective and targeted (Jupp, 2006). In this case it is noted that specific data about the issues in HRIS decisions may not be readily available. Thus, primary research may be suitable for this study.

However, there are some very important limitations of primary research. Since primary research involves an elaborate process of data collection it tends to consume significant amount of monetary resources as well as time, specifically in cases where data may be difficult to obtain (Bryman, 2001). Sampling and data collection are processes that involve third party participants and so their interests and preferences need to be taken into consideration, which could make the data collection process long and arduous. The next chapter explains the sampling methodology adopted by this research and the rationale behind the choice.

\section{Case Study}

This section of the report is focussed on the case study analysis of Information System (IS) outsourcing at Dupont, as presented by Willcocks and Feeny (2006). The authors present a core IS capability framework which shows the nine different areas of IS capabilities which 
an organisation is expected to posses. The authors argue that if an organisation lacks any of the nine core capabilities then problems would arise. The authors present the case of outsourcing at Dupont to identify the validity of the core IS model. This section of the report presents this case study in brief and identifies the various stakeholders using an appropriate framework.

\section{Sampling}

According to Webb (2002) the process of primary research involves identification of sample and design of data collection instrument. This is followed by actual collection of data and analysis of the collected data. On the basis of the results inferences are drawn and observations are made. Finally conclusions are drawn from the observations. Following diagram shows the process.

One of the most important decisions to be made in primary research is related to the choice of the sample from which data is to be collected. Before identifying the sample it is essential to be clear about the population which the research is interested in studying. In this case, this research is focused on the problems faced by companies in Arab countries, in particular Saudi Arabia, when they attempt to implement and adopt HRIS. Thus the population of this research would include the small and big businesses in Saudi Arabia . Since the size of this population could possibly be over a million, it is necessary to identify a suitable sample which would be small enough to lend to research while also be capable of representing the important properties of the businesses in Saudi Arabia in general. It was decided that this research would draw a sample of businesses from Saudi Arabia, as there is a specific geographic focus for this research. There are two different kinds of classification of businesses that had to be done for the purpose of this research. Primarily, this research is interested in studying the problems faced by small and large organisations separately and so it is essential to identify two different groups of businesses. The businesses are classified along different sectors to ensure that there are no specific sector biases in the sample. Cluster sampling was used for this purpose. Under cluster sampling, the population is divided into various clusters or groups and random samples are identified from each cluster (Marshall and Rossman, 2006). Cluster sampling ensures that each cluster gets fairly represented in the final sample so that differences between clusters may be pronounced and researched in details (Marshall and Rossman, 2006).

Four different categories were identified for classification of organisations along sectors. The four categories are Information Technology, Trading, Manufacturing and Other Services. The HR managers of different organisations were identified using social networking websites such as Orkut, MySpace and Facebook. The HR managers were then classified according to the sectors of their businesses. These potential respondents were sent requests to participate in a survey explaining the nature and uses of the survey. Those respondents that chose not to participate in the survey or did not send their confirmation were replaced by alternative ones from the same source. In the questionnaire, the respondents were also asked to specify the size of their organisation in terms of number of employees. If the number of employees were less than or equal to 100 , then these organisations were classified as 'small' and all organisations with total employee strength of over 100 were classified as 'large' for the purpose of this research. Based on the responses received it was noted that the 'large' sample had 14 respondents while the 'small' sample had 15 respondents. The nature of the business of the companies was enquired through the questionnaire in the form of one of the questions. As shown in the appendix, the questionnaire had first five questions related to the organisation while the next 11 questions were in the form of statements measured using Likert's scale to capture the opinions and responses related to HRIS. 


\section{Questionnaire Design}

For primary research, it is also essential to identify a suitable data collection method and to design an appropriate instrument. Some of the popular data collection instruments discussed for the purpose of this research are questionnaires, interviews (individual or group) and focus groups. Quantitative research incorporates the statistical element whereby numbers are used to classify the opinions, beliefs and behaviour of the target population. In quantitative research features are classified, counted, and complex statistical models are constructed in an attempt to explain what is observed. The findings from the sample are generalised over the larger population and then comparisons can be made Qualitative research has been used for studies in the field of history, geography, sociology and anthropology (Denzin and Lincoln, 1994). It is a paradigm which incorporates the movement of the researcher from philosophy to designing the research elements, and finally to data collection based on these elements (Myers, 1997). Kvale (1983) defines the qualitative research interview as "an interview, whose purpose is to gather descriptions of the life-world of the interviewee with respect to interpretation of the meaning of the described phenomena". Interviews are considered the most elaborate forms of data collection as they allow the researcher to obtain detailed response from the respondent for qualitative questions (Robson, 2002). Interviews also facilitate direct interaction between the researcher and the respondent thereby enabling active collection of information as well as knowledge acquisition for the researcher. However there are some drawbacks typically associated with using interviews as the primary means of data collection. Interviews tend to consume significant time and monetary resources. Interviews require the researcher to get in touch with each one of the respondents and so there is large-scale loss of time (Sorenson, 2002). For the respondents interviews could be highly intrusive, as they need to allocate time to participate in the interviews (Stewart and Kamins, 1993). Focus groups and Group interviews have the added advantage of active interaction among the participants and so are suitable methods in cases where interaction among the participants would add to the richness of the data collected. Questionnaires and surveys on the other hand are data collection methods that consume the least resources as questionnaires could be administered to a large number of respondents simultaneously and even from a remote location using telecom media (Sorenson and Sorenson, 2001). Objective questionnaires include answer choices for each question and so do not require the respondents to write down detailed and long answers to the questions. Objective questionnaires are easy to complete for the respondents. It was decided that the questionnaires would be completely objective in nature in which the respondents only has to choose an answer from the alternatives given for each question instead of writing down long and elaborate answers. This was done to ensure that the respondents did not suffer from fatigue or loss of interest during the course of filling the data in the questionnaire forms (Thomas, 2003). Accordingly the questionnaire used for this research includes only questions with different answer choices already given. The respondents were required to choose the most suitable answer choice for each question. The model of the questionnaire used is provided in the appendix. It can be seen that all the questions were objective in nature.

This research uses Likert scale as the basis of answer choices for the questions. Likert scale involves a series of statements expressing the favourable or unfavourable nature of the objects or entities and requires that the respondent choose one option that expresses the extent to which the respondent agrees to the statement. Likert scale is chosen as the method in this data collection process because it is quick and easy to construct and also allows the respondent to choose the closest option to reality (McDaniel and Gates, 1998). Following diagram shows the most popular Likert scale options. 


\section{Ethical Considerations and Limitations}

The methodology chosen in this research is subject to some ethical issues, which were contemplated and provided for in the research design. It was expected that the respondents would be hesitant to share information, particularly of negative nature, about their organisations of employment. In order to overcome this limitation it was decided that this research would maintain complete confidentiality and anonymity in terms of identities of the respondents as well as those of their organisations of employment. It was also believed that some respondents could consider the method of data collection intrusive and disturbing (Bryman and Bell, 2007). Therefore in order to avoid this problem, the explicit permission of the respondents to participate in the survey was obtained before they were contacted with the request to send the required information. This ensured that only those respondents who were actually interested in participating in the survey were included in the survey. Besides, the initial contacts with the respondents were made using email as the medium as email communication could be considered less intrusive in general than direct meeting or telephonic conversation (Stead, 2001). Thus this research was vulnerable to some ethical issues related to confidentiality, anonymity and privacy of the respondents. These issues were addressed using appropriate changes to the research design.

\section{Findings/Results}

This section presents a brief summary of the responses collected from the participants in primary research process. This section is divided into two parts. The first part presents details related to the nature of organisations and the roles performed by the respondents in their employer organisations. The second part, which is the most important part, discusses the responses collected for the second section of the question. This research received completed questionnaires from a total of 37 respondents. However, 5 of these response sheets were found to be incomplete and so excluded from the sample. The final sample had 18 respondents from 'large' organisations and 14 from 'small' organisations.

\section{Organisational Details}

The first five questions in the questionnaires were intended to collect some vital information about the organisations where the respondents were employed.

- 1. What is your position in your organisation?

The respondents were asked to identify their roles in their respective organisations. In the 'small' sample, $65 \%$ of the respondents played HR related roles while $33 \%$ chose 'NonHR role' as their response. Only $29 \%$ of the respondents were part of the senior management of their organisations. Another 9\% stated that they played 'other' roles in their organisations. In the large sample, $64 \%$ of the respondents stated that they played 'HR-related' roles while $21 \%$ stated that their roles were 'Non-HR'. While $9 \%$ were part of the senior management, an equal number of respondents also chose 'other' functions.

\section{- 2. Has your organisation implemented or is contemplating implementing HRIS?}

In the small sample, $73 \%$ of the respondents stated that their organisations had either already implemented or seriously contemplating implanting HRIS. According to $20 \%$ of the respondents, their organisations were not considering HRIS at the time of answering the question. $9 \%$ of the respondents did not have any idea about such decisions by their managements. In the large sample, it is noted that $86 \%$ of the organisations had already implemented or seriously contemplating the decision to implement HRIS. 14\% of the respondents stated that their organisations were not considering HRIS at that point.

- 3. What is the main business area for your organisation?

The respondents were asked to identify the main business area of their organisations. In the small sample, $35 \%$ of the organisations were in 'IT' sector while $35 \%$ were 'trading' 
businesses. While $21 \%$ were in 'manufacturing', $9 \%$ were involved in 'Other services'. In the case of large sample, $55 \%$ were involved in IT related businesses while $29 \%$ performed manufacturing activities. While 9\% were involved in trading activities, an equal number of organisations performed 'other services'.

- 4. Has your organisation engaged third-party HRIS solution providers or is the HRIS completely in-house?

In the small sample, $47 \%$ of the respondents stated that their organisations used a combination of in-house development and third-party service providers for their HRIS. While 33\% used purely in-house teams, an equal number of organisations employed only third-party service providers. On the other hand, in the large sample, $60 \%$ of the organisations used completely in-house teams for their HRIS needs while $29 \%$ used a combination of in-house and external parties. Only $27 \%$ of the respondents stated that their organisations used only third-party service providers for their HRIS implementation. - 5. Has your organisation actively undertaken HRIS implementation and decision during the years 2012-2016?

Only $20 \%$ of the respondents in the small sample stated that their organisations had made the HRIS decision during the period of economic stress between 2012 and 2016. 80\% of the organisations in the small sample had not made their HRIS decisions during this period. In the large sample, $29 \%$ of the respondents stated that their organisations made the HRIS during the adverse economic period noted in the question.

\section{HRIS}

The second part of the questionnaire included 15 statements about the nature of HRIS and decisions made with respect of HRIS in the organisations of the respondents. This subsection is concerned with presenting the brief results of the data collected in the second part of the questionnaires in this research.

The following information show the summary of responses collected for small sample and large sample.

- 6. My organisation considers HR as a strategic function.

$45 \%$ of the respondents from the 'small' sample strongly disagreed with the statement whole $9 \%$ disagreed. Only $11 \%$ strongly agreed while $25 \%$ somewhat agreed. $13 \%$ were neutral. This shows that at least $49 \%$ of the respondents disagreed with the statement in the case of 'small' sample while at least 39\% agreed. On the contrary, $48 \%$ of the respondents in the 'large' sample strongly agreed and 34\% agreed to the statement that their organisations considered HR as strategic function. Only $9 \%$ in the 'large' sample strongly disagreed to the statement.

- 7. My HR manager is part of all the important meetings related to organisational goals and objectives.

The respondents were asked to express the extent of agreement to the statement that their HR managers were part of all the important strategic meetings. It is seen than in the 'small' sample, $33 \%$ of the respondents strongly disagreed and another $23 \%$ disagreed. While $10 \%$ strongly agreed, an equal number of respondents agreed to the statement. This shows that at least $54 \%$ of the respondents in the 'small' sample expressed disagreement to the statement. $24 \%$ of the respondents were indifferent.

In the 'large' sample, $36 \%$ of the respondents strongly agreed while another $29 \%$ agreed to the statement. While 14\% disagreed, another 9\% strongly disagreed. In all $69 \%$ of the respondents at least agreed to the statement in the case of 'large' sample.

- 8. The reaction of the management team towards the HRIS proposal was positive.

This statement was intended to gauge the reaction of the management of the organisations towards the HRIS proposal in general. Only $26 \%$ of the respondents in the 'small' sample 
agreed to the statement of which $13 \%$ strongly agreed. At the other end, 59\% disagreed of which $20 \%$ strongly disagreed. $19 \%$ neither disagreed nor agreed to the statement. Overall, it is seen that most of the respondents disagreed to the statement to some extent. In the 'large' sample, it is noted that $7 \%$ if the $29 \%$ of the respondents agreed to the statement; this includes $41 \%$ who strongly agreed to the statement.

- 9. Employees' response towards HRIS proposal was positive.

After ascertaining the management's response, this questionnaire proceeds to gauge the employees' general response to HRIS. In the 'small' sample, $33 \%$ strongly disagreed while $20 \%$ agreed to the statement. $20 \%$ strongly agreed and $13 \%$ agreed. While in the 'large' sample, $50 \%$ stated that they strongly agreed to the statement while another $14 \%$ agreed. In all, $21 \%$ of the respondents expressed some kind of disagreement to the statement though $14 \%$ were neutral in their stance.

- 10. It was very easy for the HR department to secure approval for HRIS proposal.

In the 'small' sample, only 33\% agreed to the statement that their HR departments could secure permission easily from their management teams for implementation of HRIS. On the other hand 39\% disagreed, of which $13 \%$ strongly disagreed. One-third of the respondents could neither agree nor disagree. In the 'large' sample, 28\% agreed of which 9\% strongly agreed. $33 \%$ disagreed of which $14 \%$ strongly disagreed. $36 \%$ were indifferent between the two ends.

11. The senior management was not significantly worried about the secrecy and confidentiality of HR-related information while making HRIS decision.

One of the important observations made in the literature review chapter of this dissertation is that the management teams are usually concerned about the secrecy and confidentiality of their HR-related information while making their HRIS decisions. In the 'small' sample, $54 \%$ disagreed to the statement indicating that their management teams had problems associated with confidentiality of data while making HRIS decisions. Half of these respondents strongly disagreed to the statement. Only 9\% strongly agreed while 20\% agreed to the statement. On the other hand, in the 'large' sample a similar trend is visible with $58 \%$ of the respondents expressing disagreement to the statement. $21 \%$ disagreed while $21 \%$ strongly disagreed in the 'large' sample..

- 12. The HR team managed to obtain IT knowledge related to HRIS easily.

It is seen from literature review that HR teams could find it difficult to obtain the necessary IT related knowledge while adopting HRIS. 39\% of the respondents disagreed to the statement that their HR teams obtained IT knowledge easily. 13\% out of this strongly disagreed. 39\% agreed, about half of which strongly agreed to the statement. However in the case of large organisations, it appears that the HR teams do not face as much difficulties in obtaining IT knowledge as in the case of small organisations..

- 13. The HRIS software was customised to suit the needs of the HR department.

$33 \%$ of the respondents in the 'small' sample strongly agreed that their organisations had their HRIS customised to suit their needs. 39\% agreed to this statement. Only 9\% disagreed while no respondent strongly disagreed to the statement. In the case of 'large' sample, 59\% stated that they strongly agreed to the statement while another $29 \%$ somewhat agreed. While 9\% disagreed, the remaining $9 \%$ were indifferent between the extremes.

- 14. The maintenance of HRIS system is not highly cost-intensive.

In the 'small' sample, $13 \%$ each strongly disagreed, disagreed and strongly agreed to this statement while $33 \%$ agreed. One-third of the respondents neither agreed nor disagreed to the statement. In the case of 'large' sample, 14\% strongly agreed and 29\%agreed to the statement. While 14\% disagreed, an equal percentage of respondents strongly disagreed. 
- 15. The HRIS software is periodically updated to reflect changes in HR policies and procedures.

In the 'small' sample, 52\% strongly agreed to the statement that their HRIS software were periodically updated, while $35 \%$ agreed to the statement. Only $9 \%$ disagreed to this statement while another $9 \%$ were circumspect in their response. In the 'large' sample, $63 \%$ of the respondents strongly agreed while $23 \%$ agreed to the statement.

- 16. The benefits associated with HRIS justify the costs.

The final question attempts to capture the opinion of the respondent about the ability of the HRIS to justify its costs. $75 \%$ of the 'small' sample stated that their strongly agreed to the statement while another $17 \%$ agreed. Only $9 \%$ disagreed while another $9 \%$ could neither agree nor disagree. However in the 'large' sample, the results are even more conclusive as it is noted that a huge $93 \%$ of the respondents strongly agreed to the statement that the benefits of HRIS outweigh costs.

\section{Analysis and Discussion}

As it can be seen from the first chapter, this research attempts to find answers to two important questions. The first question is related to the different problems faced by organisations and the second question enquires if these problems are different for large and small organisations. This section compares the findings from literature review and the primary research to identify the major problems and to ascertain if these are different for small and large organisations.

"What are the problems faced by organisations in developing countries, while adopting and implementing HRIS?"

According to Singh (2002) the organisations in developing countries typically tend to change their rules and procedures to suit the HRIS system rather than customising the system to suit their rules and procedures. In such cases, the author argues that HRIS could lead to failures. However this does not appear to be a major problem in the case of organisations in Saudi Arabia as it is noted that both small and large organisations tend to customise their HRIS to a significant extent even though large organisations appear to have a higher degree of customisation in their HRIS. The primary data show that $89 \%$ of organisations in small sample and $85 \%$ of organisations in large sample have customised HRIS to a significant extent. IOMA (2002) has found in a survey that the organisations with small budgets could find HRIS a difficult decision to make. Primary research shows that this is indeed a problem among the organisations in developing countries as only $39 \%$ of small sample and $41 \%$ of large sample found HRIS to be less intensive on cost. Thus it can be noted that high costs of HRIS is a major common problem faced by small and large organisations. The next question identifies the problems that are different for small and large organisations.

"Are the problems related to HRIS faced by small organisations different from those faced by large organisation",

In the literature review chapter it is seen from the analysis of the research by Lawler (1995) and Brockbank (1999) that the management teams tend to attach low importance to HR managers, which complicates the process of HRIS adoption and decision-making. Researchers including Langbert and Friedman (2002), Budhwar and Bhatnagar (2009) and Heeks (2002) have made similar observations in the specific context of developing countries. It is seen from the primary data that the small organisations typically tend to attach low importance to HR departments in Saudi Arabia, as they do not treat HR as a strategic function. $60 \%$ of the respondents in small sample agreed to this. However, the large organisations tend to treat HR as a strategic function, as $86 \%$ of respondents confirm and so the problem of low degree of importance to HR is present significantly only in 
small organisations. It is also noted that the large organisations tend to include HR managers in critical business meetings thereby providing them opportunities to pitch the idea of HRIS adoption successfully to the management.

Jossi (2000) argues that the employees exhibit a level of inertia towards adopting new ways of working including HRIS. It is observed from the primary research that this is a problem mostly in small organisations and not in large organisations as it is noted that the employees in large organisations tend to have a positive attitude towards HRIS proposal. This is evident from the fact that 33\% of respondents in small sample and $64 \%$ of respondents in large sample found positive response from employees towards HRIS. Hannon et al. (1996) state that the initial problems for HRIS proposals could arise from the management team itself as the senior managers may be hesitant towards a cost-intensive project such as HRIS. However it is noted from primary research that this is a problem only in the case of small organisations. Only $26 \%$ in small sample found positive response from management towards HRIS while $29 \%$ in large sample found favourable response from management. The management teams in large organisation appear to exhibit a more favourable response towards HRIS proposals in general than the small organisations.

A detailed review of the existing literature has been undertaken in order to acquire theoretical knowledge about the issues and problems faced by organisations with respect to HRIS. The literature review shows that during the pre-implementation stage, the organisations faced issues related to management decision-making (Lawler, 1995; Brockbank, 1999) and high cost of HRIS (Langbert and Friedman, 2002). Besides, it is also noted that the lack of importance attributed to HR department and HR manger could bring problems to HRIS during this stage. During the stage of implementation, the biggest issue is that the organisation may fail to get the system completely customised to suit the needs and preferences of the organisation (Singh, 2002). The unwillingness and hesitance on the part of employees to learn new IT skills necessary to derive benefits from the system could also be an issue in this stage (Hagood and Friedman, 2002; Jossi, 2000). In small organisations, the costs associated with maintenance and upgrading of the HRIS on a continuous basis could be considered too high in relation to the other costs incurred by the organisation. In order to verify the validity of these secondary research observations, a primary research is undertaken in the form of survey conducted using the employees of randomly chosen organisations from Saudi Arabia as the sample. Analysis of the data collected using the survey shows that there are some very important differences between small and large organisations in terms of the issues and problems faced. While the large organisations tend to attach great significance to the HR function, the small organisations usually tend to attribute a non-strategic administrative role to the HR managers. While the large organisations tend to use more of their internal know-how for HRIS implementation and development, small organisations are dependent more on the external specialists (Greer et al., 1993; Taplin, 2007). The small organisations also have smaller budgets than the larger organisations.

\section{Conclusion}

The wide acceptance of scientific management and the proliferation of multinational companies owing to globalisation have made HRIS popular among organisations around the world. Even though originally used only by very large organisations with thousands of employees, HRIS has now become common even among small organisations with only a few hundred employees. Even though there has been an increasing awareness among organisations in the developing countries about the potential benefits of HRIS, there are some issues involved in these organisations while making the decision to adopt HRIS as well as during the implementation phase. The objective of this research was to study the 
problems encountered by the organisations in developing countries in relation to HRIS adoption and implementation. This research also enquires if these problems are significantly difference for small and large organisations. The case of Saudi Arabia is used in this research as a representative for developing countries.

This research is conducted within strict cost and time constraints, which have determined the depth and breadth of this research. However if any researcher can work with more flexible cost and time constraints it may be possible to bring about some important improvements in this research. It is suggested that the research should take into account the case of another developing country in addition to Saudi Arabia, to possibly identify any country-specific variations in the problems faced by organisations. It may also be helpful to widen the sample to include more sub-sectors in order to determine any sector specific issues related to HRIS. Besides, it is also suggested that the researcher can consider expanding the size of the sample to obtain responses from a large number of respondents so that any possible biases could be minimised. These suggestions are targeted at the researchers who may undertake research into the same topic in future.

\section{References}

Afiouni, F., Rulkl, H. and Schuler, R. (2014) 'HRM In The Middle East: Toward A Greater Understanding'. The International Journal of Human Resource Management 25 (2), 133143

Alhazemi A. A. , (2016) Recommendations for Improving the Way University of Jeddah Handles Learning and Training Activities, International Journal of Advanced Biotechnology and Research ,7(4) 0976-2612

Alhazemi, A. A. , Ali W.,( 2016), The Notion of Work Life Balance, Determining Factors, Antecedents and Consequences: A Comprehensive Literature Survey, International Journal of Academic Research and Reflection. 4 (8), 74-85

Bagad, V. S. (2008) Management Information Systems, Technical Publications.

Baldwin, L. P., Irani, Z. and Love, P. E. D. (2001) 'Outsourcing information systems: drawing lessons from a banking case study', European Journal of Information Systems, 10, 15-24.

Beulen, E. (2009) 'The contribution of a global service provider's Human Resources Information System (HRIS) to staff retention in emerging markets: Comparing issues and implications in six developing countries', Information technology \& People, 22, 3 270288.

Brockbank, W. (1999) 'If HR were really strategically proactive: Present and future directions in HR's contribution to competitive advantage', Human Resource Management, 38, 337352.

Bryman, A. and Bell, E. (2007) Business research methods, Oxford University Press.

Budhwar, P. S. and Bhatnagar, J. (2009) The Changing Face of People Management in Saudi Arabia, Taylor \& Francis.

Cameron, E. and Green, M. (2004) Making sense of change management: a complete guide to the models, tools \& techniques of organizational change, Kogan Page Publishers.

Ceriello, V. R and Freeman, C. (1998) Human Resource Management Systems: Strategies, Tactics and Techniques, San Francisco: Jossey-Bass.

Chmielecki, M. (2012) 'HR challenges in China'. Journal of Intercultural Management 4 (3), 4955.

Collins. D. (2000) Management Fads and Buzzwords: Critical-Practical Perspectives, London: Routlege.

Cooper, H. M., Hedges, L. V. and Valentine, J. C. (2009) The handbook of research synthesis and meta-analysis, Russell Sage Foundation.

Elliot, R. H. (1999) 'Computer literacy and human resource management: A public/private sector comparison', Public Personnel Management, 28, 2 259-275. 
Garton, L., Haythornthwaite, C., \& Wellman, B. (1999). Studying on-line social networks. In S. Jones (Ed.), Doing Internet Research: Critical Issues and Methods for Examining the Net (pp. 75-105). Thousand Oaks, CA: Sage.

Gharajedaghi, J. (1999) ystems thinking: managing chaos and complexity : a platform for designing business architecture, Elsevier.

Graetz, F. (2000) 'Strategic change leadership', Management Decision, 38(8), 550-562.

Greer, C. R., Youngblood, S. A. and Gray, D. A. (1993) 'Human Resource Management Outsourcing: The Make or Buy Decision', The Academy of Management Executive, 13, 3 85-96.

Hagood, W. O. and Friedman, L. (2002) 'Using the balanced scorecard to measure the performance of your HR information system', Public Personnel Management, 31, 4 543-558.

Hannon, J., Jelf, G. and Brandes, D. (1996) 'Human resource information systems: Operational issues and strategic considerations in a global environment', International Journal of Human Resource Management, 7, 1 17-32.

Heeks, R. (2002) 'Information Systems and Developing Countries: Failure, Success and Local Improvisations', The Information Society, 18, 2 101-112.

International Association for Human Resource Information Management (2002) Boundaryless HR: human capital management in the global economy, Rector-Duncan.

IOMA (2002) Report on Managing HR Information Systems - How to resolve conflicts with HRIS project team members, March 6-7.

Jossi, F. (2001) 'Get the most out of HRIS training', HR Magazine, 46, 3 121-126.

Jupp, V. (2006) The Sage dictionary of social research methods, Pine Forge Press.

Kehal, H. S. and Singh, V. P. (2006) Outsourcing and offshoring in the 21st century: a socioeconomic perspective, Idea Global Inc.

Khalfan, A. (2003) 'A case analysis of business process outsourcing project failure profile and implementation problems in a large organisation of a developing nation', Business Process Management Journal, 9(6), 745-759.

Khasawneh, A. Alhazemi .A. (2015), - Human resource management and healthcare employee's motivation a comparison study in Saudi Arabia public and private hospitals, International Journal of Current Research, Vol. 7, Issue, 03, pp. 13573-13578, March, 2015

Koib, B. (2008) Marketing Research: A Practical Approach, Sage Publications.

Kotter, J. P. (2000) 'What Leaders Really Do', The Bottom Line: Managing Library Finances, 13(1).

Kovach, K. A. and Cathcart, C. E. (1999) 'Human Resource Information Systems (HRIS): Providing Business with Rapid Data Access, Information Exchange and Strategic Advantage', Public Personnel Management, 28(2), 275-281.

Kvale, Steinar (1983). The qualitative research interview: A phenomenological and a hermeneutical mode of understanding. Journal of Phenomenological Psychology, 14, 171-196.

Lauder, D., Boocock, G., Presely, J. (1994), "The system of support for SMEs in the UK and Germany", European Business Review, Vol. 94 No.1, pp.9-16.

Lawler, E. E. (1995) 'Strategic human resources management: An idea whose time has come', In B. Downie and M. L. Coates (Eds.), Managing human resources in the 1990s and beyond: Is the workplace being transformed? (pp. 46-70), Kingston, Canada: IRC Press.

Llieva, J., Baron, S., \& Healey, N. M. (2002). Online surveys in marketing research: Pros and cons. International Journal of Market Research, 44 (3), 361-367.

Marshall, C. and Rossman, G. B. (2006) Designing qualitative research, Sage Publications.

Martinsons, M. G. (1994) 'Benchmarking human resource information systems in Canada and Hong Kong', Information and Management, 26, 305-316.

Mayfield, J., Mayfield, M. and Lunce, S. (2003) 'Human Resource Information Systems: A Review and ModelDevelopment', Advances in Competitiveness Research, 11(1), 139-151.

McDaniel, C. D. and Gates, R. H. (1998) Marketing research essentials, Taylor \& Francis.

Mclvor, R. (2005) The outsourcing process: strategies for evaluation and management, Cambridge University Press. 
Miyajima, K. 2017. “What Influences Bank Lending in Saudi Arabia?” IMF Working Paper 17/31, International Monetary Fund, Washington, DC.

Moran, J. W. and Brightman, B. K. (2001) 'Leading organizational change', Career Development International,6(2), 111-118.

Mutahseb, A. (2004). The Internet as an Alternative Source of Information and Alternative Forum of Expression for Arab Americans. Unpublished Ph.D. dissertation. University of Memphis.

Nayak, A., \& Pandey, M. (2015). Work-Life Balance and Imbalance:A Conceptual Model, Vidyasagar University Journal of Commerce, 20, 181-192.

Ngai, E. W. T and Wat, F. K. T (2006) 'Human resource information systems: A review and empirical analysis', Personnel Review, 35, 3 297-314.

Novo, M., Hammarstrom, A. and Janlert, U. (2000) 'Health hazards of unemployment-only a boom phenomenon? A study of young men and women during times of prosperity and times of recession', Public Health, 114(1), 25-29.

Paton, R. and McCalman, J. (2000) Change Management: A Guide to Effective Implementation, Sage.

Poutanen, H. (2005) 'Human Resource Information Systems and Human Resource Management in Organizations', in Remenyi, D. (2005) Proceedings of the 12th European Conference on IT Evaluation (ECITE 2005), Academic Conferences Limited.

Quinn, J. B. and Hilmer, F. G. (1994) 'Strategic outsourcing', Sloan Management Review, 35(4), $43-55$.

research

Reynolds, G. W. (1995) Information systems for managers, West Pub. Co.

Robson, C. (2002) Real world research, Wiley-Blackwell.

Schwab, D. P. (2005) Research methods for organizational studies, Routledge.

Senior, B. (2002) Organizational Change, London: Pitman.

Singh, M. (2002) 'Issues related to selection and implementation of IHRIS: A study of 10 organizations', IHRIM Journal, 6, 5 45-54.

Sorenson, O. and Sorenson, J. B. (2001) 'Finding the right mix: Franchising, organizational learning, and chain performance', Strategic Management Journal, 22(6/7), 713-724.

Sorenson, S. (2002) How to Write Research Papers, Peterson's.

Stead, G. B. (2001) Planning, designing and reporting research, Pearson South Africa.

Stewart, D. W. and Kamins, M. A. (1993) Secondary research, New York: SAGE.

Tannenbaum, S. (1990) 'HRIS user group implications', Journal of Systems Management, 41(1), 27-32.

Taplin, R. (2007) Outsourcing and human resource management: an international survey, Routledge.

Thomas, R. M. (2003) Blending qualitative \& quantitative research methods in theses and dissertations, California: Corwin Press.

Todnem, R. B. (2005) 'Organisational Change Management: A Critical Review', Journal of Change Management, 5(4), 369-380.

Webb, J. R. (2002) Understanding and designing market research, Cengage.

Weisbord, M. R. (1976) 'Organizational Diagnosis: Six Places To Look for Trouble with or Without a Theory', Group \& Organization Management, 1(4), 430-447.

Wellman, B., \& Haythornthwaite, C. (Eds.) (2002). The Internet in Everyday Life. Oxford, UK: Blackwell.

Willcocks, L. P. and Feeny, D. (2006) 'IT Outsourcing and core IS capabilities: Challenges and lessons at Dupont', Information Systems Management, Winter 2006, 49-56.

Willis, J. W., Willis, J., Jost, M. and Nilakanta, R. (2007) Foundations of qualitative research: interpretive and critical approaches, Sage Publications.

Young, S. (2008) 'Outsourcing in public health: a case study of contract failure and its aftermath', Journal of Health, Organization and Management, 22(5), 446-464. 